\title{
Impaired glucose tolerance after streptozotocin microinjection into the mediodorsal prefrontal cortex of the rat
}

\author{
B Nagy, I Szabó, G Takács, B Csetényi, E Hormay, Z Karádi \\ Institute of Physiology, School of Medicine, University of Pécs, Pécs, Hungary
}

Received: December 28, 2015

Accepted: September 5, 2016

\begin{abstract}
The mediodorsal prefrontal cortex (mdPFC) is a key structure of the central glucose-monitoring (GM) neural network. Previous studies indicate that intracerebral streptozotocin (STZ) microinjection-induced destruction of local chemosensory neurons results in feeding and metabolic alterations. The present experiments aimed to examine whether STZ microinjection into the mdPFC causes metabolic deficits. To do so, glucose tolerance test (GTT) and measurements of plasma metabolites were performed in STZ-treated or control rats. Intraperitoneal D-glucose load was delivered $20 \mathrm{~min}$ or 4 weeks following the intracerebral microinjection of STZ or saline (acute or subacute GTT, respectively). The STZ-treated rats displayed acute glucose intolerance: at the 120th min of the test, blood glucose level of these rats was significantly higher than that of the ones in the control group. When determining the plasma level of various metabolites, $30 \mathrm{~min}$ following the intracerebral STZ or saline microinjection, the triglyceride concentration of the STZ-treated rats was found to be reduced compared with that of the control rats. The GM neurons of the mdPFC are suggested to be involved in the organization of complex metabolic processes by which these chemosensory cells contribute to adaptive control mechanisms of the maintenance of homeostasis.
\end{abstract}

Keywords: forebrain limbic circuitry, mediodorsal prefrontal cortex, glucose-monitoring neurons, STZ, glucose intolerance, hypotriglyceridemia

\section{Introduction}

The prefrontal cortex (PFC) is implicated in various regulatory processes, including cognitive functions, attention, working memory, drive and motivation, and organization of goaloriented behaviors like food and fluid intake $(5,16,17,24)$. In addition to these already known regulatory functions, the PFC was recently shown to play an important role in glucoreception as well (27).

The homeostatically important process of glucoreception has been demonstrated originally in some visceral organs, and later also in the peripheral, then, in the central nervous systems (CNSs). By investigating the peripheral nervous system, Niijima (29) observed that glucose injection of the portal vasculature reduced discharge frequency of hepatic vagal fibers in guinea pigs. A further step was the discovery of the existence of the socalled glucose-monitoring (GM) neurons in the CNS $(2,31,32)$. These cells detect changes in the extracellular glucose concentration, in addition, they also utilize glucose as a signaling modulator molecule to alter firing rate. The GM neurons have to be distinguished from the

Corresponding author: Bernadett Nagy, MD

Institute of Physiology, School of Medicine, University of Pécs

Szigeti st. 12, H-7624 Pécs, Hungary

Phone: +36 72 536245; Fax: +36 72 536424; E-mail: bernadett.nagy@aok.pte.hu 
glucose-insensitive cells that use the glucose only in their metabolism and do not show activity changes to it at all (30).

The existence of neurons that are a part of the GM neural network has already been verified in brain regions mutually interconnected with each other and the PFC, such as the lateral hypothalamic area, ventromedial hypothalamic nucleus (VMH), amygdala, globus pallidus (GP), nucleus accumbens, orbitofrontal (OBF) cortex, nucleus tractus solitarii, and in the area postrema (AP) $(1,3,11,12,14,19,34)$. The GM neurons have also been discovered in the mediodorsal PFC (mdPFC) composed by neuroanatomical subdivisions of the PFC, such as the prelimbic and cingulate cortices (27). GM neurons of the mdPFC possess special neurochemical responsiveness: their distinct dopamine and remarkable acetylcholine sensitivities are suggested to be of distinguished significance in the prefrontal cortical control of adaptive behaviors $(26,27)$.

Streptozotocin (STZ) - a chemical naturally produced by Streptomyces achromogenes is known to selectively destroy insulin producing $\beta$-cells of the pancreatic islets of Langerhans. Correspondingly, it is widely used to induce experimental type 1 diabetes mellitus, creating an effective animal model of the disease $(8,39)$. Therapeutic application of STZ is limited, due to its severe side effects, to treating primary insulinomas. The STZ is similar enough to glucose to be selectively transported into the cells by the type 2 glucose transporter protein (GLUT2), and it has not been shown to be recognized by other type glucose transporters. After entering the cell via GLUT2, STZ - among others - causes alkylation and consequent fragmentation of DNA and its cytotoxic action includes reactive oxygen species mediated oxidative stress mechanisms (39). The toxic effect of STZ is exerted not only in the pancreatic $\beta$-cells; it has been reported that intracerebral microinjection of STZ decreases glucose utilization and glycolytic processes of certain brain areas $(6,36)$. According to the previous findings of our laboratory, similar intracerebral STZ microinjections destroy the GLUT2 positive chemosensory (GM) neurons in various brain areas (e.g., VMH, OBF cortex, PFC, and GP) causing severe deficits of feeding and metabolism $(7,11-13,15)$.

Despite the recent emerging of scarce and indirect data in the literature $(23,25,28)$, little is known yet about the involvement of prefrontal cortical neurons in the central metabolic control.

In the present experiments, therefore, to eliminate local chemosensory neurons, STZ was microinjected bilaterally into the mdPFC of rats, and acute and subacute glucose tolerance tests (GTTs) were performed as well as plasma metabolite levels determined to elucidate metabolic significance of chemosensory (GM) cells of the mdPFC.

\section{Materials and Methods}

Male Wistar rats $(n=97)$ with an average body weight of 270-340 g were housed individually in a temperature and light controlled room $\left(21 \pm 2{ }^{\circ} \mathrm{C} ; 12-12 \mathrm{~h}\right.$ light-dark cycle) where constant humidity $(55 \%-60 \%)$ was assured. Tap water and laboratory chow food were $a d$ libitum available for the rats except where it is stated differently. The rats were divided into two randomized and counterbalanced, evenly formed groups on the basis of their body weight. A control GTT was performed before the experiments to select the unhealthy subjects. Twelve rats $(12.3 \%$ of all rats) with impaired glucose tolerance were excluded from the further analysis.

Anesthetized rats $(n=85$, intraperitoneal ketamine, $50 \mathrm{mg} / \mathrm{ml}, 0.3 \mathrm{ml} / 100 \mathrm{~g} \mathrm{bw})$ were operated on stereotaxically, their scalp was incised, and a small (4-5 $\mathrm{mm}$ in diameter) hole was drilled through the cleaned skull. Guide cannulas made of $23 \mathrm{G}$ stainless steel pipettes were placed on the surface of the dura above the mdPFC by a mechanical microdrive 
(MN-33 Narishige, Japan). After positioning, the guide cannulas were fixed to the cranium using anchoring screws and dental acrylic.

Following a week-long recovery period, microinjection cannulas (30 G) were passed through these guide cannulas to deliver the chemicals directly to the mdPFC. Stereotaxic coordinates for mdPFC according to the stereotaxic rat brain atlas of Pellegrino et al. (35) were: AP: $+3.7 \mathrm{~mm}$ anterior to bregma (B), mediolateral (ML): $1 \mathrm{~mm}$, and vertical (V): $1.5 \mathrm{~mm}$ from dura (Fig. 1). Alert, previously well-handled rats were microinjected bilaterally with either $7.5 \mu \mathrm{g}$ STZ (Sigma S-0130, $10 \mu \mathrm{g} / \mu \mathrm{l}$; dissolved in sterile physiological saline) or sterile physiological saline alone. Solutions were microinjected by a microinfusion pump (Cole Parmer 789200C) in a volume of $0.75 \mu \mathrm{l}$ for $1 \mathrm{~min}$ through a stainless steel microinjection cannula extending $1.5 \mathrm{~mm}$ below the tips of the guide cannula fixed on the skull with dental acrylic. Microinjection cannulas were left in place for one more minute to help diffusion of solutions into the target area.

The standardized GTT was performed after a $12 \mathrm{~h}$ food deprivation of the rats $(n=29)$. Intraperitoneal injection of $20 \%$ D-glucose solution $(0.2 \mathrm{~g} / 100 \mathrm{~g} \mathrm{bw} / \mathrm{ml})$ was administered at the 20th min following the intracerebral microinjection of STZ or saline (acute GTT) and then 4 weeks later (subacute GTT). Blood samples were taken from the tail of rats and the measurements were performed by glucometer (Glucometer Elite, Bayer, Germany).

In another animal group $(n=56)$, relevant plasma metabolites [total cholesterol, highdensity lipoprotein (HDL), triglycerides (TGs), and uric acid] were determined after a 12-h food deprivation and $30 \mathrm{~min}$ after the bilateral STZ or saline microinjection by a semiautomatic cold chemistry photometer (Spotchem EZ SP4430, Arkray, Japan).

After finishing all experiments, the rats were intraperitoneally overdosed with urethane and transcardially perfused with physiological saline followed by $4 \%$ formalin. The brains were fixed in $4 \%$ formalin, then frozen and cut in $40 \mu \mathrm{m}$ sections. Nissl (cresyl violet) staining was used to examine and identify the exact site of microinjections. Rats with inappropriate cannula positions $(n=4)$ were excluded from the further analysis.

In the GTT experiment, blood glucose levels of the animal groups were compared and statistically analyzed. Similarly, statistical analysis was also performed for plasma metabolites of rats of the STZ-treated and control groups. All results are reported as means \pm SEM. Analysis of variance (one-way ANOVA) and Tukey's test for post hoc comparisons were used for statistical analysis. Differences were considered to be significant at $p<0.05$.

All experimental procedures were conducted in accordance with institutional, national, and international regulations (BA02/2000-8/2012, Pécs University, Medical School; Law XXVIII, 1998, Government Decree 40/2013, Hungary; NIH Guidelines 1997, European Community Council Directive 86/609/EEC 1986, 2006; European Directive 2010/63/EU of the European Parliament).

\section{Results}

GTT

Investigations of acute and subacute glucose tolerance after bilateral STZ or vehicle microinjection into the mdPFC were performed in 29 adult male Wistar rats. Seventeen rats were treated by STZ, whereas 12 control rats received physiological saline microinjection. The first GTT was performed $20 \mathrm{~min}$ after the intracerebral microinjection (acute GTT), whereas the second GTT was performed 4 weeks later (subacute GTT). 


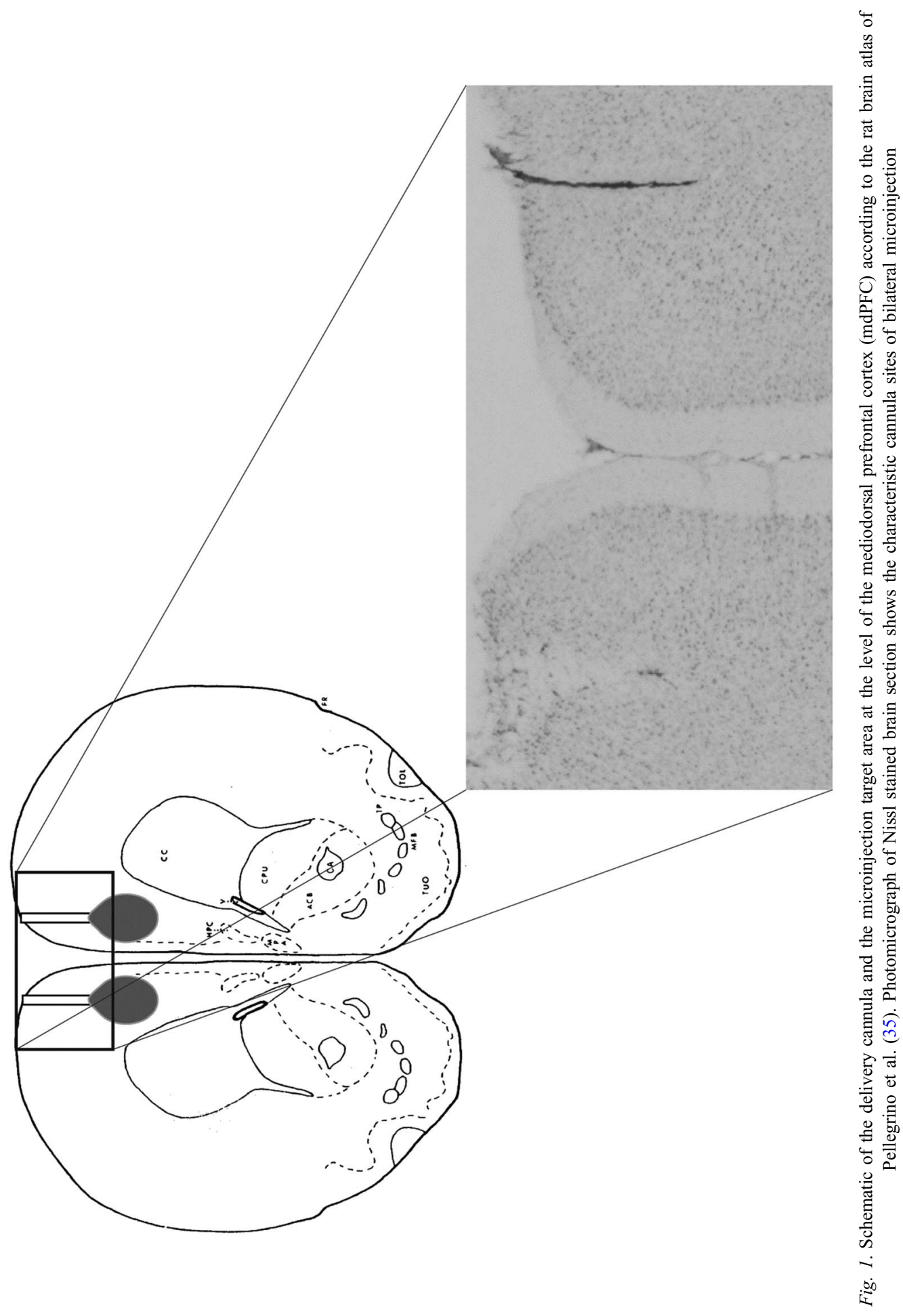


(a)

$$
\begin{aligned}
& \text { Acute GTT } \\
& 0 \mathrm{~min}
\end{aligned}
$$

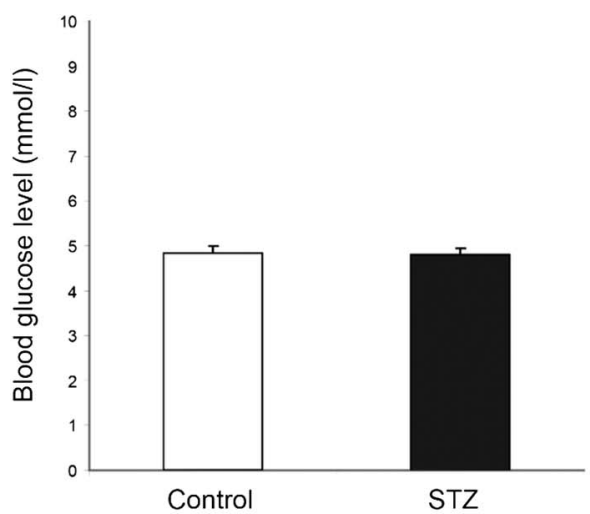

(b)

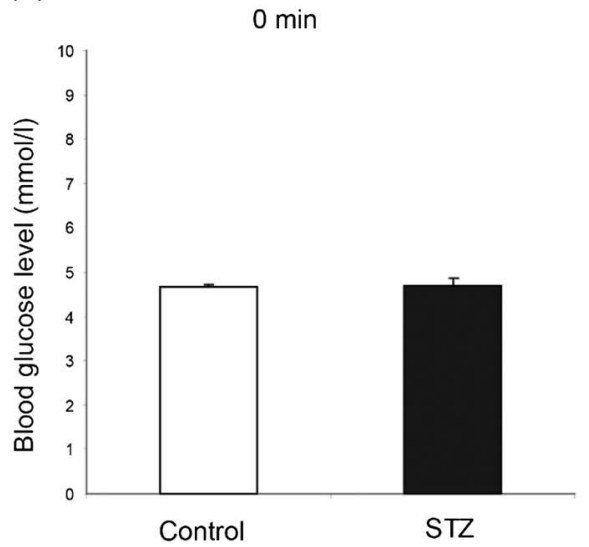

Acute GTT 120th min

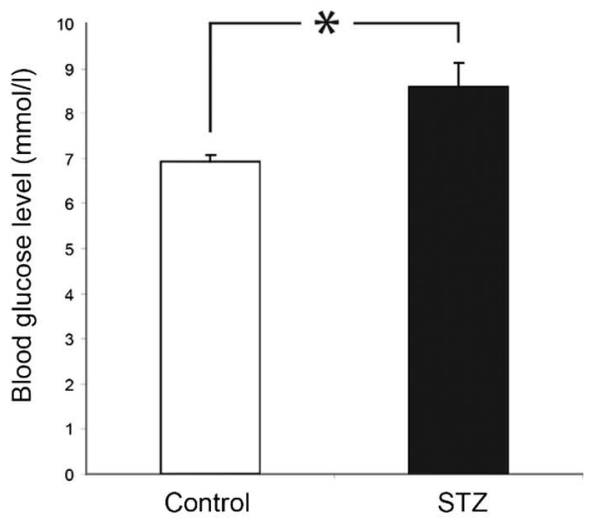

Subacute GTT 120th $\mathrm{min}$

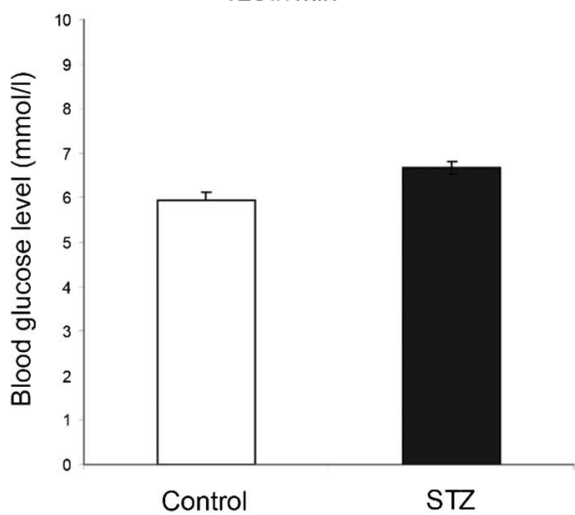

Fig. 2. Impaired glucose tolerance in the acute GTT after bilateral streptozotocin (STZ) microinjection into the mdPFC. (a) Fasting blood glucose levels of STZ-treated $(n=17)$ and control groups $(n=12)$ did not differ significantly. Two hours after the intraperitoneal glucose injection, however, blood glucose concentrations of the

STZ-treated rats significantly increased compared with the control rats $\left({ }^{*} p<0.05\right)$. Columns represent the mean blood glucose levels \pm SEM. (b) Four weeks following the STZ or physiological saline microinjection (subacute phase), the glucose tolerance was physiological in both groups: both the fasting and the 120th min's blood glucose levels of the rats were found to be in the similar range

Pathological alterations of blood glucose levels and a definite glucose intolerance of the STZ-treated rats became obvious in the acute GTT. The ANOVA test showed a significant group difference in the acute GTT $\left(F_{3,57}=35.164 ; p<0.05\right)$. The fasting blood glucose levels were almost the same in the two groups (control: $4.84 \pm 0.16 \mathrm{mmol} / \mathrm{l}$ and STZ: $4.81 \pm$ $0.12 \mathrm{mmol} / \mathrm{l}$, respectively). However, $2 \mathrm{~h}$ after the intraperitoneal glucose injection, blood glucose level of the STZ-treated rats was significantly higher than that of the rats in the control group (control: $6.95 \pm 0.14 \mathrm{mmol} / 1$ and STZ $8.6 \pm 0.51 ; p<0.05$ ). The results are shown in Fig. 2a. 
In the subacute phase, there was no significant difference between the fasting blood glucose concentrations of the STZ-treated and control groups (control: $4.74 \pm 0.09 \mathrm{mmol} / \mathrm{l}$ and STZ: $4.76 \pm 0.12 \mathrm{mmol} / \mathrm{l})$. Although the 120th min's blood glucose levels appeared to be higher in the rats subjected to STZ microinjection (control: $5.90 \pm 0.21 \mathrm{mmol} / \mathrm{l}$ and STZ: $6.72 \pm 0.18 \mathrm{mmol} / \mathrm{l}$ ), there was no significant difference between the two groups (Fig. $2 \mathrm{~b}$ ).

\section{Plasma levels of metabolites}

In a separate series of experiments with 52 adult male Wistar rats, $30 \mathrm{~min}$ after the bilateral intracerebral microinjection into the mdPFC, plasma concentrations of total cholesterol, TG, HDL, and uric acid were determined. Twenty-seven rats were treated by STZ-treated and 25 control rats received physiological saline microinjection. Plasma concentrations of total cholesterol, HDL, and uric acid in the STZ-treated and control groups did not differ from each other. At the same time, however, significantly reduced plasma TG levels were detected in the rats with mediodorsal prefrontal cortical STZ microinjection (control: $0.66 \pm 0.03 \mathrm{mmol} / \mathrm{l}$ and STZ: $0.56 \pm 0.03 \mathrm{mmol} / 1, p<0.05)$. The results are shown in Fig. 3 .

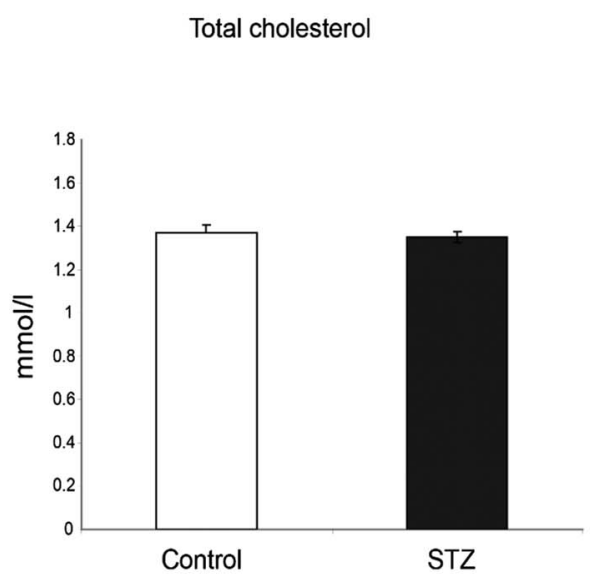

HDL

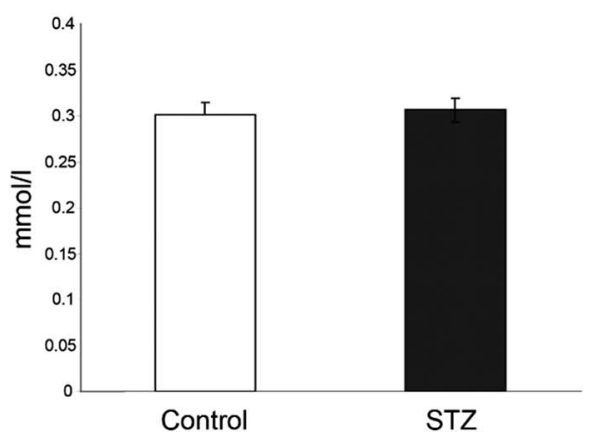

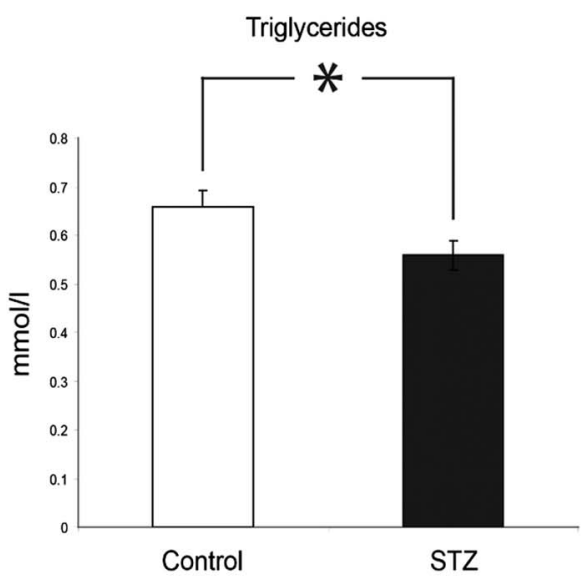

Uric acid

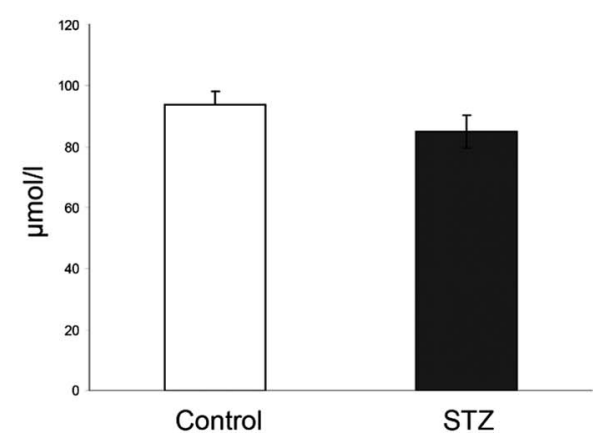

Fig. 3. Plasma levels of metabolites of the STZ-treated $(n=27)$ and control $(n=25)$ rats 30 min following the intracerebral microinjection. All results are reported as means \pm SEM. The plasma concentrations of total cholesterol, HDL, and uric acid in the STZ-treated and control rats did not differ significantly. Significant reduction of plasma TG levels was found, however, in the STZ microinjected group $(* p<0.05)$ 


\section{Discussion}

In the present study, evidence was obtained for the intimate involvement of mdPFC neurons in the central regulation of metabolism. The results of our studies, first time in the literature, show that complex metabolic alterations develop as a consequence of bilateral mdPFC microinjection of STZ. Selective destruction of the STZ sensitive neurons led to temporary diabetes-like impaired glucose tolerance and altered TG level. The changes were characteristically selective since other tested parameters (total cholesterol, HDL, and uric acid plasma concentrations) and the subacute GTT did not show any significant difference between the STZ-treated and control rats.

In the healthy organism, the CNS takes part in the sophisticated control of metabolic processes using integrating metabolic (degraded nutrients, fatty acids, amino acids, ketone bodies, lactic acid, various metabolites, etc.), humoral-hormonal (e.g., insulin, leptin, GLP-1, etc.), and complex neural information coming from the periphery as well as from particular chemosensory neurons of various brain structures $(12,20,33,38)$. Since the physiologically effective metabolism that maintains the balance of homeostasis among broad environmental conditions is dependent upon central sensing of the relevant peripheral signals, altered sensitivity of these special neurons may result in severe metabolic disturbances that lead to such feeding-metabolic diseases as, e.g., obesity and diabetes mellitus are (20).

Among patients with type 1 diabetes mellitus (T1DM), associations between metabolic control measures and shrinkage of the prefrontal cortical thickness were found. Patients with T1DM, relative to healthy control subjects, had thinner cortex in the prefrontal cortical areas. Long-term glycemic control measures, expressed by the average value of $\mathrm{HbA1c}$, were found to be associated with bilateral thickness reduction in the superior prefrontal cortical regions (21). The healthy human brain shows significant levels of hierarchical organization characterized by connections for top-down control with minimum wiring cost (37). Relative absence of hierarchically high-level hubs in the PFC of patients with T1DM was found, which suggests ineffective top-down control of the PFC in T1DM (22). All these data substantiate the important role of PFC in the control of carbohydrate metabolism.

Several data in the literature support the view that GLUT2, at least partially, is involved in cerebral glucose sensing $(4,18)$. STZ, which at the periphery was shown to enter the $\beta$-cells via GLUT2, has been demonstrated to also exert toxic effects in several brain regions. Intracerebroventricular administration of STZ was observed to result in significant reduction of glucose utilization and glycolytic processes $(6,36)$. The toxic effect of STZ on certain neurons, among others the GM ones, may get exerted via GLUT2 associated mechanisms. It is important to mention, however, that an in vitro study raised doubts concerning the role of GLUT2 in glucose sensing in the VMH, indicating a gatekeeper role of glucokinase in the cerebral glucose sensing (10). Nevertheless, a previous study of ours revealed deficits of hypothalamic GLUT2 immunolabeling after STZ microinjection into the VMH of the rat (40), and the present findings also support our hypothesis that the mdPFC neurons, among them the local constituents of the limbic forebrain GM neural network, play an essential role in the maintenance and preservation of the homeostatic balance.

One of our previous pilot studies showed that STZ treatment of the mdPFC caused elevation of plasma concentration of insulin (unpublished observations), but it is evident that further investigations are needed to confirm these results. Damage to these chemosensory 
neurons appears to elicit and maintain complex feeding and metabolic disturbances. A single bilateral microinjection of STZ into either the VMH or OBF cortex was found to cause glucose intolerance and alterations of concentrations of plasma metabolites (12). STZ microinjection into the VMH caused decreased total cholesterol and increased TG levels, while STZ microinjection into the OBF resulted in significant decrease of plasma total cholesterol and TG levels. In the STZ-treated rats, in the present study, similar to the above findings, the decrease of plasma TG concentrations was observed. Based on all these data, it is reasonable to suppose that prefrontal cortical constituents of the forebrain GM network participate in the central regulation of feeding and metabolism. It takes place supposedly using complex control mechanisms, in part also determined by the existing multiple functional morphological interrelationships of these structures. The significance of these data is further underlined by the results of recent experiments revealing that high-fat/ cholesterol diet increases plasma TG, total cholesterol, non-HDL, and HDL cholesterol levels in rodents with a subsequent activation of cholinergic processes within the PFC, along with cognitive impairments $(23,25)$, or by demonstrating the causal role of mdPFC D1 dopamine receptors in modifying high-fat food seeking (28). It is already a textbook material that decreased TG can be due to hepatic failure, but our metabolic data - physiological level of cholesterol and lactate dehydrogenase $(\mathrm{LDH})$ - do not indicate liver failure. Instead, the decrease of TG concentration may be considered as a consequence of complex regulatory disturbance whose exact mechanism still remains to be revealed.

Feeding and metabolic disorders like obesity, diabetes mellitus, or metabolic syndrome cause increasing burden on the modern societies. The presently used therapeutic approaches these days targeting the peripheral pathology so far could not fully resolve the problems; consequently, at present, the above diseases cannot be cured yet. It is reasonable to suppose that this is at least in part because dysfunction of the central GM neurons is ignored in the evaluation of the above-mentioned illnesses. The physiological functioning of these neurons appears to be indispensable with respect to the maintenance of the homeostatic balance since these cells influence energy balance regulation in a complex manner by simultaneously affecting multiple factors of homeostasis, such as energy intake and energy expenditure, thermoregulation, and various other factors as well (9).

Our present findings support the view that disturbance of the regulatory processes of the CNS should necessarily to be taken into consideration in elucidating the background of the above-mentioned diseases. With respect to this CNS involvement, the role of GM neurons here appears to be especially important. They integrate complex chemical and other information of various sources, which predestinate them to play significant adaptive role in the central regulation of feeding and metabolism.

Considering all of the above, we hope that the better understanding of complex functional attributes of mdPFC chemosensory neurons and those of other brain structures important in the maintenance of homeostasis can lead to the identification of new drug targets and the discovery of successful new therapeutic strategies as well.

\section{Acknowledgements}

The authors would like to thank Ildikó Fuchs and Erzsébet Korona for their valuable technical assistance. This work was supported by Ajinomoto Co. (51064/2009), PTE AOK-KA 2013/34039/1 and S.R.O.P. 4.2.4.A/2-11-1-20120001 "National Excellence Program." 


\section{REFERENCES}

1. Adachi A, Shimizu N, Oomura Y, Kobashi M: Convergence of hepatoportal glucose-sensitive afferent signals to glucose-sensitive units within the nucleus of the solitary tract. Neurosci. Lett. 46, 215-218 (1984)

2. Anand BK, Chhina GS, Sharma KN, Dua S, Singh B: Activity of single neurons in the hypothalamic feeding centers: effect of glucose. Am. J. Physiol. 207, 1146-1154 (1964)

3. Aou S, Oomura Y, Lenard L, Nishino H, Inokuchi A, Minami T, Misaki H: Behavioral significance of monkey hypothalamic glucose-sensitive neurons. Brain Res. 302, 69-74 (1984)

4. Arluison M, Quignon M, Nguyen P, Thorens B, Leloup C, Penicaud L: Distribution and anatomical localization of the glucose transporter 2 (GLUT2) in the adult rat brain - an immunohistochemical study. J. Chem. Neuroanat. 28, 117-136 (2004)

5. Baldwin AE, Sadeghian K, Kelley AE: Appetitive instrumental learning requires coincident activation of NMDA and dopamine D1 receptors within the medial prefrontal cortex. J. Neurosci. 22, 1063-1071 (2002)

6. Duelli R, Schrock H, Kuschinsky W, Hoyer S: Intracerebroventricular injection of streptozotocin induces discrete local changes in cerebral glucose utilization in rats. Int. J. Dev. Neurosci. 12, 737-743 (1994)

7. Egyed R, Lukats B, Karadi Z: Diabetes mellitus-like metabolic deficits elicited by ventromedial hypothalamic streptozotocin microinjection. J. Physiol. (Lond.) 526, 173-174 (2000)

8. Ganda OP, Rossini AA, Like AA: Studies on streptozotocin diabetes. Diabetes 25, 595-603 (1976)

9. Garami A, Székely M: Body temperature: its regulation in framework of energy balance. Temperature (Austin) 1(1), 28-29 (2014)

10. Kang L, Routh VH, Kuzhikandathil EV, Gaspers LD, Levin BE: Physiological and molecular characteristics of rat hypothalamic ventromedial nucleus glucosensing neurons. Diabetes 53, 549-559 (2004)

11. Karádi Z, Lukats B, Papp S, Szalay C, Egyed R, Lenard L, Takacs G: Involvement of forebrain glucosemonitoring neurons in taste information processing: electrophysiological and behavioral studies. Chem. Senses 30(Suppl. 1), i168-i169 (2005)

12. Karádi Z, Lukats B, Papp S, Takacs G, Egyed R, Lenard L: The central glucose-monitoring neural network: major protector of the adaptive homeostatic balance for well being of the organism. International Congress Series 1269, 30-33 (2004)

13. Karádi Z, Nagy B, Szabó I, Szalay C, Takács G, Keresztes D, Hideg B, Faragó B, Góré MB, Lénárd L: Complex functional attributes of forebrain glucose-monitoring neurons in the maintenance of homeostasis. Acta Physiol. (Oxf.) 202(Suppl. 684), O20 (2011)

14. Karádi Z, Oomura Y, Nishino H, Scott TR, Lenard L, Aou S: Responses of lateral hypothalamic glucosesensitive and glucose-insensitive neurons to chemical stimuli in behaving rhesus monkeys. J. Neurophysiol. 67, 389-400 (1992)

15. Keszthelyi Z, Past T, Lukats B, Koltai K, Karadi Z: The central effect of chromium on glucose metabolism. Pharmacopsychiatry 37, 242 (2004)

16. Kolb B: Functions of the frontal cortex of the rat: a comparative review. Brain Res. 320, 65-98 (1984)

17. Kolb B, Nonneman AJ: Prefrontal cortex and the regulation of food intake in the rat. J. Comp. Physiol. Psychol. $88,806-815$ (1975)

18. Leloup C, Arluison M, Lepetit N, Cartier N, Marfaing-Jallat P, Ferre P, Penicaud L: Glucose transporter 2 (GLUT 2): expression in specific brain nuclei. Brain Res. 638, 221-226 (1994)

19. Lénárd L, Karadi Z, Faludi B, Czurko A, Niedetzky C, Vida I, Nishino H: Glucose-sensitive neurons of the globus pallidus: I. Neurochemical characteristics. Brain Res. Bull. 37, 149-155 (1995)

20. Levin BE: Metabolic sensing neurons and the control of energy homeostasis. Physiol. Behav. 89, 486-489 (2006)

21. Lyoo IK, Yoon S, Jacobson AM, Hwang J, Musen G, Kim JE, Simonson DC, Bae S, Bolo N, Kim DJ, Weinger K, Lee JH, Ryan CM, Renshaw PF: Prefrontal cortical deficits in type 1 diabetes mellitus: brain correlates of comorbid depression. Arch. Gen. Psychiatry 69, 1267-1276 (2012)

22. Lyoo IK, Yoon S, Renshaw PF, Hwang J, Bae S, Musen G, Kim JE, Bolo N, Jeong HS, Simonson DC, Lee SH, Weinger K, Jung JJ, Ryan CM, Choi Y, Jacobson AM: Network-level structural abnormalities of cerebral cortex in type 1 diabetes mellitus. PLoS One 8, e71304 (2013)

23. Moreira EL, de Oliveira J, Engel DF, Walz R, de Bem AF, Farina M, Prediger RD: Hypercholesterolemia induces short-term spatial memory impairments in mice: up-regulation of acetylcholinesterase activity as an early and causal event? J. Neural Transm. (Vienna) 121, 415-426 (2014)

24. Morgane PJ, Galler JR, Mokler DJ: A review of systems and networks of the limbic forebrain/limbic midbrain. Prog. Neurobiol. 75, 143-160 (2005) 
25. Morgenstern I, Ye Z, Liang S, Fagan S, Leibowitz SF: Involvement of cholinergic mechanisms in the behavioral effects of dietary fat consumption. Brain Res. 1470, 24-34 (2012)

26. Nagy B, Szabo I, Csetenyi B, Hormay E, Papp S, Keresztes D, Karadi Z: Noradrenaline and acetylcholine responsiveness of glucose-monitoring and glucose-insensitive neurons in the mediodorsal prefrontal cortex. Brain Res. 1543, 159-164 (2014)

27. Nagy B, Szabo I, Papp S, Takacs G, Szalay C, Karadi Z: Glucose-monitoring neurons in the mediodorsal prefrontal cortex. Brain Res. 1444, 38-44 (2012)

28. Nair SG, Navarre BM, Cifani C, Pickens CL, Bossert JM, Shaham Y: Role of dorsal medial prefrontal cortex dopamine D1-family receptors in relapse to high-fat food seeking induced by the anxiogenic drug yohimbine. Neuropsychopharmacology 36, 497-510 (2011)

29. Niijima A: Glucose-sensitive afferent nerve fibres in the hepatic branch of the vagus nerve in the guinea-pig. J. Physiol. 332, 315-323 (1982)

30. Oomura Y (1980): Input-output organisation in the hypothalamus relating to food intake behaviour. In: The Handbook of the Hypothalamus II, eds Morgane PJ, Panksepp J, Marcel Dekker Inc., New York, NY, USA, pp. 557-620

31. Oomura Y, Kimura K, Ooyama H, Maeno T, Iki M, Kuniyoshi M: Reciprocal activities of the ventromedial and lateral hypothalamic areas of cats. Science 143, 484-485 (1964)

32. Oomura Y, Ono T, Ooyama H, Wayner MJ: Glucose and osmosensitive neurons of the rat hypothalamus. Nature 222, 282-284 (1969)

33. Pannacciulli N, Le DS, Salbe AD, Chen K, Reiman EM, Tataranni PA, Krakoff J: Postprandial glucagon-like peptide-1 (GLP-1) response is positively associated with changes in neuronal activity of brain areas implicated in satiety and food intake regulation in humans. Neuroimage 35, 511-517 (2007)

34. Papp S, Lukats B, Takacs G, Szalay C, Karadi Z: Glucose-monitoring neurons in the nucleus accumbens. Neuroreport 18, 1561-1565 (2007)

35. Pellegrino LJ, Pellegrino AS, Cushman AJ (1979): A Stereotaxic Atlas of the Rat Brain. Plenum Press, New York, NY, USA

36. Plaschke K, Hoyer S: Action of the diabetogenic drug streptozotocin on glycolytic and glycogenolytic metabolism in adult rat brain cortex and hippocampus. Int. J. Dev. Neurosci. 11, 477-483 (1993)

37. Ravasz E, Barabasi AL: Hierarchical organization in complex networks. Phys. Rev. E Stat. Nonlin. Soft Matter Phys. 67, 026112 (2003)

38. Rocca AS, Brubaker PL: Role of the vagus nerve in mediating proximal nutrient-induced glucagon-like peptide-1 secretion. Endocrinology 140, 1687-1694 (1999)

39. Szkudelski T: The mechanism of alloxan and streptozotocin action in B cells of the rat pancreas. Physiol. Res. 50, 537-546 (2001)

40. Telkes I, Szalay C, Lénárd L, Karádi Z: Deficits of hypothalamic GLUT2 immunolabeling after streptozotocin microinjection into the ventromedial hypothalamic nucleus of the rat. Front. Neurosci. 5, 2-31 (2011) 